\title{
Community monitors as researchers: determining vulnerable species distribution in a protected area of central Mexico
}

\author{
O. Eric Ramírez-Bravo'*, E. Evangelina Camargo-Rivera², E. Morales Manuel Osmar ${ }^{3}$, Edna A. Contreras Aldana ${ }^{3}$, \\ Alejandro Pastén Sánchez ${ }^{3}$, Patricio Cano Flores ${ }^{4}$, C. Enrique Espinoza Pérez ${ }^{4}$ \& Florencio Sixto Ramírez ${ }^{4}$ \\ 'Department of Biodiversity, Feeding and Climate Change, Sciences Institute, Benemérita Universidad Autónoma de Puebla, Edi- \\ ficio Val 4, Ecocampus Valsequillo, Carretera Puebla-Tetela, San Pedro Zacachimalpa, Mexico \\ 2.Motocle A.C. San Andrés Cholula, Av. Maximino Ávila Camacho 1019-9, San Andrés Cholula, Puebla, Mexico; e-mail: Evan- \\ gelina.camargo@gmail.com \\ ${ }^{3}$ Biological Sciences Faculty, Benemérita Universidad Autónoma de Puebla, 14 Sur 6301, Col. San Manuel, Puebla, Mexico \\ ${ }^{4}$ Community Monitors from the Hydrographic Basin of the Necaxa River Protected Area, Santa Dora, 73172 Huauchinango, Pue, \\ Mexico \\ *Corresponding author, email: osvaldoeric.ramirez@correo.buap.mx
}

ABSTRACT

We designed a training workshop in biodiversity monitoring and natural resources management and conservation for rural communities of the Hydrographic Basin of the Necaxa River Protected Area, aiming to increase active participation. We presented 2 cases in which participants documented 2 vulnerable species, increasing the distribution of margay, Leopardus wiedii Schinz, 1821 (Mammalia Felidae) and recording the persistence of neotropical otter, Lontra longicaudis Olfers, 1818 (Mammalia Mustelidae). These records proved that with proper training, community monitors could generate new information on biodiversity distribution, provide evidence to traditional knowledge, and produce data to improve protected area management.

KEY WORDS C Citizen science; Leopardus wiedii; Lontra longicaudis; Necaxa River; Puebla.

Received 08.10.2019; accepted 13.02.2020; published online 22.02.2020

\section{INTRODUCTION}

Public participation in scientific projects can provide a significant input as it can help to determine different aspects whether from species (Gandiwa, 2012; Petracca et al., 2014; Kotschwar et al., 2015) or ecosystems and the use of natural resources (De la Ossa et al., 2011). However, participation varies among different projects according to their necessities. As in protected areas, capacities vary among communities; we developed a workshop for key participants covering biodiversity monitoring and management, project administration, and legislation. We aimed to generate facilitators in each community in order to increase interest in biodiversity conservation inside protected areas. In this paper, we present two cases in which community monitors have undertaken biodiversity monitoring methodologies to document range expansions of margay (Leopardus wiedii Schinz, 1821) and persistence of otter (Lontra longicaudis Olfers, 1818) in the Necaxa River.

We developed the workshop in the protected area "Cuenca Hidrográfica del Río Necaxa" in Central Mexico (between the parallels $20^{\circ} 3^{\prime}$ and $20^{\circ} 14^{\prime}$ of latitude north and $97^{\circ} 51^{\prime}$ and $98^{\circ} 13^{\prime}$ of west longitude). It has a very marked altitudinal variation that goes from 560 meters a.s.l. up to 2,323 meters a.s.l. and a considerable variation of ecosystems: pine forests, oak forests, pine-oak forests, mountain 
mesophile forests and medium sub-deciduous forests (Cerón-Carpio et al., 2012). The cases we present correspond to a community in conserved pine forests with isolated patches of medium subdeciduous forests (Parque ecológico "La Venta") and one community in evergreen tropical forest (El Pozo).

\section{MATERIAL AND METHODS}

As part of the workshop, we included how to use camera traps, undertake transects to determine the presence of tracks and scats according to Aranda (2000). We provided each community with 2 Bushnell Natureview camera traps that were set along paths at the height of about $30 \mathrm{~cm}$ to $40 \mathrm{~cm}$ and changed every 15 days, from February to July 2018.

In this work, we present the report of each species.

\section{RESULTS AND CONCLUSIONS}

The animal species registered with this photographic survey system are the following:

\section{Margay (Leopardus wiedii)}

Monitors from the community of Venta Grande set camera traps in the Ecoturistic Park La Venta accumulating a total of 579 camera/nights. During this period, monitors obtained photos of three individuals of undetermined sex in nearby areas in the days: 17 March 2018 at 09:34, 29 March 2018 at 03:26 and 21 April 2018 at 19:56 (Figs. 1-3). The individuals were identified thanks to their size in the photographs, the spot patterns, and the tail-body relation (Aranda, 2000; De Oliveira, 1998; De Oliveira et al., 2015).

Additionally, we recorded other mammal species such like Cacomixtle, Bassariscus astutus (Lichtenstein, 1830) and Raccoon, Procyon lotor (Linnaeus, 1758) (Procyonidae), Opossum, Didelphis virginiana (Kerr, 1792) (Didelphidae), Grey Fox, Grey Chipmunk, Sciurus spp. (Sciuridae), Urocyon cinereoargenteus (Schreber, 1775) and Feral Dogs (Canis familiaris Linnaeus, 1758 (Canidae). The Margay was previously reported in the state (Botello et al., 2006; Ramírez-Bravo \&
Hernandez-Santin, 2016); however, our records are important for the reserve as they extend the distribution of the species $25 \mathrm{~km}$ to the west of the nearest report inside the protected area (Ramírez-Bravo \& Hernandez-Santin, 2016). Furthermore, it is the first time in the area that a margay is spotted above

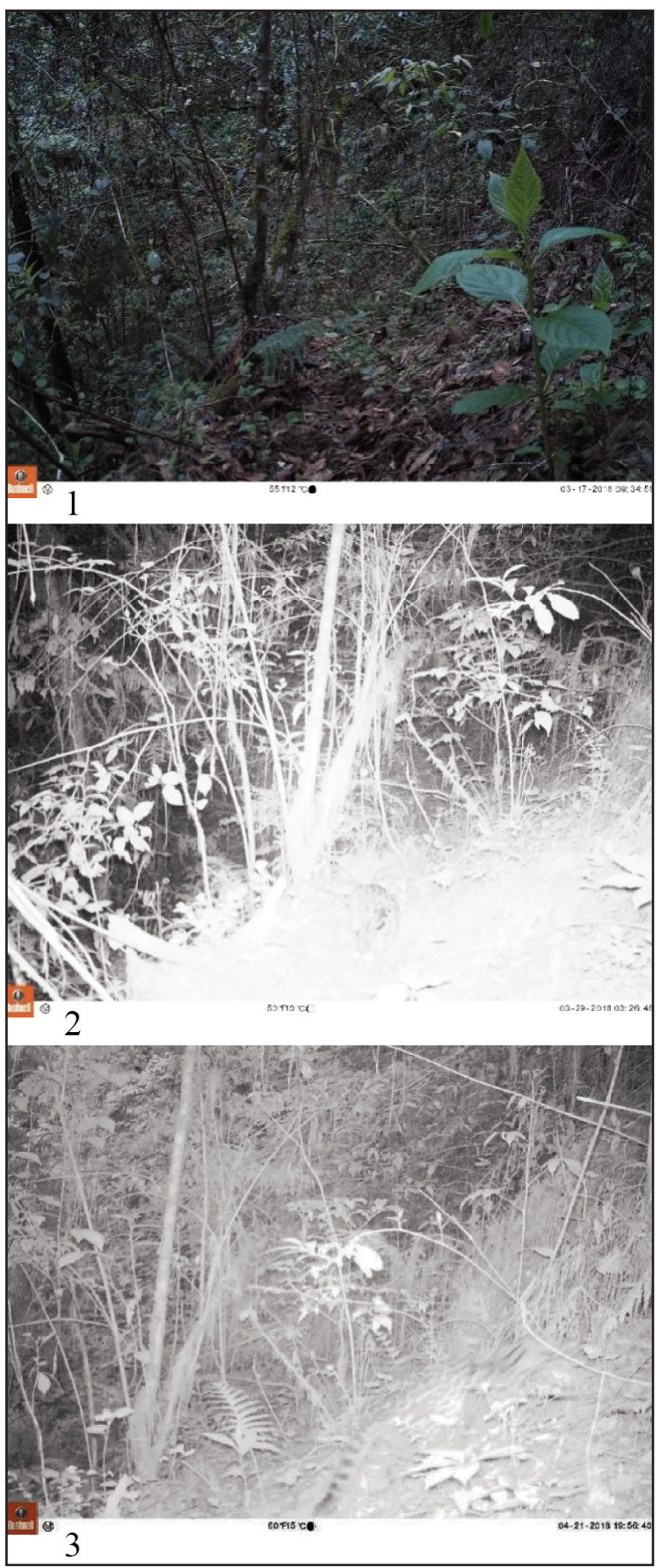

Figures 1-3. Margay (Leopardus wiedii) records obtained with camera trap. 


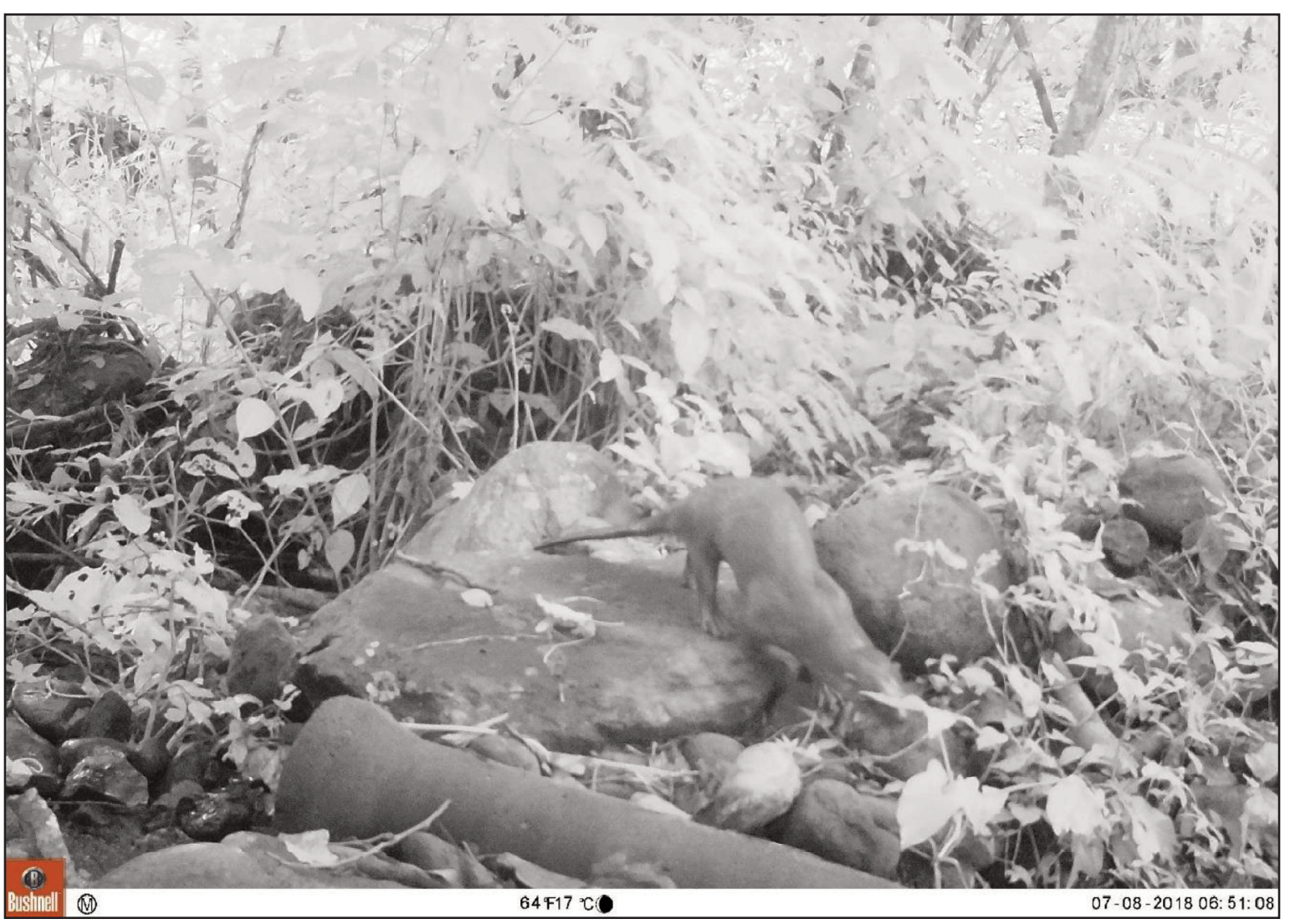

Figure 4. Otter (Lontra longicaudis) obtained by camera traps.

the 2,000 meters a.s.1. in an area with pine forest as predominant habitat. In terms of management, the use of camera traps has helped to determine species presence and illegal hunting occurring inside the Ecotouristic Park.

\section{Otter (Lontra longicaudis)}

Community monitors from the municipality of Zihuateutla set camera traps in tropical rainforest, accumulating a total of 300 camera/nights. During this period, monitors obtained a photo of an Otter of undetermined sex near the Necaxa river on 8 July 2018 at 06:51 (Fig. 4).

Additionally, we recorded other mammal species such as Coati, Nasua narica (Linnaeus, 1766), and Raccoon Procyon lotor (Procyonidae) and Opossum, Didelphis virginiana (Didelphidae). Although the record is not new to the zone (Ramírez-Bravo \& Hernandez-Santin, 2016), it shows that the otter continues using the available habitat along the river.

\section{ACKNOWLEDGEMENTS}

We want to thank the program of professional development for full-time Professors (PRODEP), which gave the financing through the scholarship PTC-558, and the authorities of the Protected Natural Area Cuenca Hidrográfica del Río Necaxa for the given facilities in order to fulfil this project.

\section{REFERENCES}

Aranda M., 2000. Huellas y otros rastros de los mamíferos grandes y medianos de México. Instituto de Ecología, A.C., Xalapa, México, 260 pp.

Botello F., Illoldi-Rangel P., Linaje M. \& SánchezCordero V., 2006. Primer registro del tigrillo (Leopardus wiedii Schinz, 1821) y del gato montés (Lynx rufus Kerr, 1792) en la Reserva de la Biosfera de Tehuacán-Cuicatlán, Oaxaca, México. Acta zoológica mexicana, 22: 135-139.

Cerón-Carpio A.B., Contreras-Jiménez J.L. \& De Gante- 
Cabrera V.H., 2012. Pteridofloristic inventory of the natural resource protection area "Necaxa River Hydrographic Basin" portion Puebla, Mexico. Polibotanica, 33: 41-55.

De la Ossa V.J. \& De la Ossa-Lacay A., 2011. Cacería de subsistencia en San Marcos, Sucre, Colombia. Revista Colombiana De Ciencia Animal, 3: 213-224. https:/doi.org/10.24188/recia.v3.n2.2011.367

De Oliveira T.G., 1998. Leopardus wiedii. Mammalian species, 579: 1-6.

De Oliveira T., Paviolo A., Schipper J., Bianchi R., Payan E. \& Carvajal S.V., 2015. Leopardus wiedii. The IUCN Red List of Threatened Species 2015: e. T11511A50654216. December 2018 http://dx.doi. org/10.2305/IUCN.UK.2015-4.RLTS.T11511A5065 4216.en.

Gandiw E., 2012. Local knowledge and perceptions of animal population abundances by communities adja- cent to the northern Gonarezhou National Park, Zimbabwe. Tropical Conservation Science, 5: 255-269.

Kotschwar Logan M., Gerber B.D., Karpanty S.M., Justin S. \& Rabenahy F.N., 2015. Assessing carnivore distribution from local knowledge across a human dominated landscape in central southeastern Madagascar. Animal Conservation, 18: 82-91. https://doi. org/10.1111/acv.12137

Petracca L.S., Ramírez-Bravo O.E \& Hernández-Santín L., 2014. Occupancy estimation of jaguar Panthera onca to assess the value of east-central Mexico as a jaguar corridor. Oryx, 48: 133-140. https://doi.org/ 10.1017/S0030605313000069

Ramírez-Bravo O.E. \& Hernandez-Santin L. 2016. Carnivores (Mammalia) from areas of NearcticNeotropical transition in Puebla, central Mexico: presence, distribution, and conservation. Check List, 12: 1833. https://doi.org/10.15560/12.11833 